\title{
Fear of Crime in Residential Areas
}

\section{Siti Rasidah Md Sakip ${ }^{1}$, Aldrin Abdullah ${ }^{1}$, Mohd Najib Mohd Salleh ${ }^{2}$}

\author{
${ }^{1}$ Faculty of Architecture, Planning \& Surveying, University Technology Mara Perak, Malaysia \\ 2 School of Housing, Building \& Planning, University Science of Malaysia, Malaysia sitir704@perak.uitm.edu.my \\ sitir704@perak.uitm.edu.my
}

\begin{abstract}
Physical environmental elements such as gated elements are believed to have an effect towards the reduction of fear of crime in residential neighbourhoods. In Malaysia, the typical form of residences is that involving gated individual houses, while residences without gated elements are relatively a new development concept. Therefore, a survey on fear of crime among residents in housing areas with gated and non-gated residences was conducted in Bandar Baru Bangi, Selangor and Precinct 9B, Putrajaya. This research discovered that respondents inhabiting a gated residential area exhibit a higher fear of crime level $(M=5.84, S D=1.23)$ when compared to respondents living in a non-gated residential area $(\mathrm{M}=3.85, \mathrm{SD}=1.66)$.

Keywords: Crime, fear of crime, gated and non-gated residential areas, confirmatory factor analysis

eISSN 2514-751X @ 2018. The Authors. Published for AMER ABRA CE-Bs by e-International Publishing House, Ltd., UK. This is an open access article under the CC BY-NC-ND license (http://creativecommons.org/licenses/bync-nd/4.0/). Peer-review under responsibility of AMER (Association of Malaysian Environment-Behaviour Researchers), ABRA (Association of Behavioural Researchers on Asians) and CE-Bs (Centre for EnvironmentBehaviour Studies), Faculty of Architecture, Planning \& Surveying, Universiti Teknologi MARA, Malaysia.

DOI: https://doi.org/10.21834/aje-bs.v3i7.261
\end{abstract}




\subsection{Introduction}

Fear of crime has become a serious social problem demanding scientific understanding and social reaction (Renauer, 2007). In reducing fear of crime, physical elements such as gated elements become a crucial factor. Hence, the gated community residential concept has caught the attention of developers. Therefore, its attracted popular demand due to the belief that the gated element is able to reduce acts of crime in residential areas and reduce fear of crime (Atkinson, Blandy, Flint \& Lister, 2004; Blakely \& Snyder, 1997; JPBD, 2009; Setha Low, 2004 \&Thuillier, 2003). However, in Malaysia typical residential developments comprise elements of gating at every individual lot. While the concept, of non-gated individual residential units is still seldom applied. In Malaysia, the development of gated community residential concept entails two elements of gate namely at every individual lot and also around the perimeter of the residential area which coupled with a security guard post at the entrance to the residential area. Thus, the practice of the gated community residential areas in Malaysia known as a gated and guarded community which targeted at the higher income earners (JPBD, 2009). Therefore, the objectives of this study are to investigate the feeling of fear of crime among residents in gated and non-gated individual residential areas within the Malaysian context. Gated residential areas in this study can be defined as a residential area which fenced according to individual lots and no control for access and egress to the housing area itself. Access and egress control is only within the individual lots and normally utilizes the fencing element or together with other security systems such as closed circuit television (CCTV), dogs and others. In addition to this, the definition used for non-gated residences in this study referred to individual lots within residential areas that are unfenced and have no access or egress control such as gated elements, either within the individual lots or at the overall residential neighborhood area.

\subsection{Literature Review}

Crime is a social problem commanding national attention. According to the National Crime Victimization Survey Report (Bureau of Justice Statistics, 2002), estimated 24.2 million crimes occurred in 2001. The cost to victims, their families and the general public in monetary terms is of considerable magnitude. The estimated total cost of crime in 1994 was 19.58 billion dollars. The categorized costs of crime such as cost in anticipation of crime', cost as a consequence of crime' and cost in response to crime' (Supt Goh Boon Keng, 2006). In Malaysia, the total cost of crime in 2004 can be divided into two categories, which are criminal justice system costs and crime costs. The estimated total costs of those crimes were RM15,359 million (Supt Goh Boon Keng, 2006). Although the cost in monetary terms is visible, the social cost of crime, such as the fear of becoming a victim of crime, is less apparent (Hale, 1996). In fact, the fear of crime purported to be higher than actual crime rates and the effect of fear of crime causes individuals to implement avoidance strategies such as staying in at night or avoiding certain areas (Fowler \& Mangione, 1986; Stiles, Halim, \& Kaplan, 2003).

Fear of crime is a manifestation of a feeling that one is in danger. According to Pain (2000), fear of crime is not an inherent characteristic of individuals, but rather something that 
may come and go, dependent on and influenced byone'sexperiences, especiallyasthey relate to one's position in society. The feeling of fear of crime is differs and depends on the situation in which one feels fear of crime (Schneider \& Kitchen, 2007), design and the environment (Spinks, 2001), aswellastheirpsychologicaland social life factors (Minnery \& Lim, 2005). Fear of crime influenced by five factors, which are the physical environment (Harang, 2003; Nasar \& Fisher, 1993), social environment (Ross \& Jang, 2000), victimization (Banks, 2005), crimespecific (British Crime Survey, 2008), and crime problems in the neighborhood (Gibson, Zhao, Lovrich, \& Gaffney, 2002). The physical environment is the utilization of fixed elements caused by physical planning and design (Nasar \& Fisher, 1993) and believed to give a significant effect on fear of crime (Harang, 2003). Meanwhile, the social environment factors involve subjective matters such as social problems and familial economic systems involving human relationships (Ross \& Jang, 2000). As reported by O'Shea (2006), concerns on the social environment caused by the individual's unacceptable behaviour such as public drunkenness, drug addiction, prostitution, juvenile loitering, delinquent behaviour and homelessness (Renauer, 2007; Welsh \& Hoshi, 2002). The third factor is victimization. There have two types of victimization, namely direct and indirect victimization. Direct victimization refers to someone who has been a real victim of crime (Nasar \& Fisher, 1993) whilst indirect victimization is when there is a fear of crime upon hearing the news of crime either from experiences of being a crime victim among relatives, friends, neighbours or from the media (Banks, 2005) which caused a traumatic feeling and fear on personal safety should become a victim of crime (Reid, 2000).

Crime problems in neighbourhoods and crime-specific is the other factors that frequently affect the feeling of fear of crime. According to Gibson, Zhao, Lovrich and Gaffney (2002), crime problems in neighbourhoods often measured by asking respondents to rate how high the crime problem is in their neighbourhoods within a period of 12 months. Meanwhile, crime-specific measures a respondent's general sense of safety (Ferraro \& LaGrange, 1987). The measure taps emotional fear by asking respondents how often they worry about specific types of crime.

As a result of society's fear of burgeoning crime, the quality of their life has slid. Based on the Quality of Life Report Malaysia 2004, urban society in Malaysia has seen deterioration in the quality of their life from the aspect of security. This security aspect measured based on crime rates and road accident statistics. The report indicated that during the period of 1990 to 2002, the public security index has gone down by 19.9 points. Average criminal cases have risen from 3.8 cases in 1990 to 6.2 cases in 2002. The security component has become more critical as in recent times the incidences of crimes involving snatch thefts, burglary and petty thefts have become more frequent. The security aspect closely associated with social peace of mind and both is pre-requisites for a steady and stable development (UPE, 2004).

\subsection{Methodology}

The research method included a structured questionnaire, which administered in the context of face-to-face structured and formal interviews. The settings of the interviews were the 
preselected residential areas in Presint 9 in Putrajaya and Seksyen 4 Bandar Baru Bangi. The focus of this study involves groups of residents earning a medium high level of income between RM3000 to RM5000 and categorized as able to afford medium high cost houses (JPBD, 2009; Putrajaya, 2009). The study employs the population survey approach on individual gated residential (IGR) areas in Bandar Baru Bangi and individual non-gated residential (INR) areas in Putrajaya. In IGR, it involved 275 households and 201 households in INR. The study's respondents comprised of heads of households or the main breadwinner in the household. A preliminary site study conducted to identify unoccupied residences such as neighbourhood watch beats, kindergartens, child care centres, storage buildings and vacant residences. Out of 476 residences, 19 eliminated from the respondent selection list as they identified as having non residential use. Out of 457 residences, only 171 respondents contribute in this study. The selection of INR done first followed by the selection of IGR. In Malaysia, INR are very limited and Putrajaya chosen as the study area because it is the first INR in Malaysia to practice the nongated concept (Roslan Talib, 2009).

\subsection{Results and Discussions}

The validation of the fear of crime construct with five dimensions, namely, physical environment $(\mathrm{PE})$, social environment (SE), indirect victimization (VIC), crime-specific (CS), and crime problems in residential (CPR) areas done by conducting a confirmatory factor analysis (CFA) using AMOS and SPSS software. CFA is a measurement model which developed by the correlation between latent variables and several indicators (items) or known as variable and error manifests. The CFA method is able to ensure and validate the items used in measuring latent variables by taking into account the value of the variances. The result of the measurement model for fear of crime construct is as shown in Figure 1.

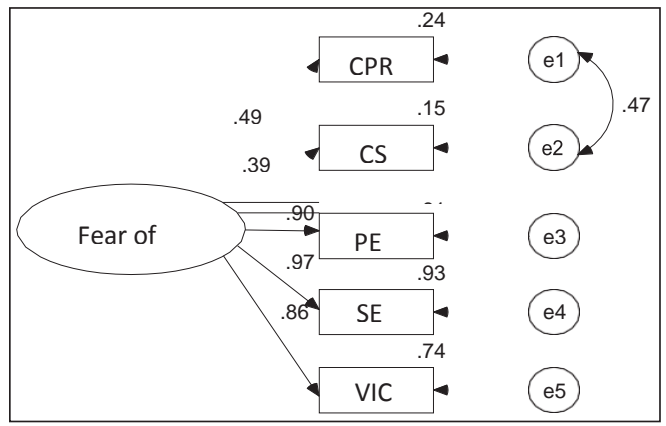

Figure 1: Measurement Model on Fear of Crime Construct

Figure 1 demonstrates the measurement model for fear of crime (FOC) construct. The results show the factor loading value for every dimension of fear of crime, which are $\operatorname{CPR}(0.49), \operatorname{CS}(0.39), \operatorname{PE}(0.90), \operatorname{SE}(0.97)$, and $\mathrm{VIC}(0.86)$ are more than 0.3 , which shows 
the suitability of each item in measuring the latent variable (fear of crime) (Sellin \& Keeves, 1997). Apart from the factor loading value, several indices employed to judge whether the model tested fits to the data, such as Chi-square, Chi-square/degree of freedom ratio, and goodness of fit indices. According to Hair, Black, Babin dan Anderson (2006), the construct of fear of crime achieves good fit between the models and the data because the model is not significant $\left(X^{2}(4)=5.051, p>0.05\right)$, the value of Goodness of Fit Index $(G F I)=0.98$, Normed Fit Index $(\mathrm{NFI})=0.99$, Comparative Fit Index $(\mathrm{CFI})=0.99$, Tucker- Lewis Index $(\mathrm{TLI})=0.99$, are more than 0.09 , and Root Mean Square of Approximation (RMSEA) is less than 0.05 .

Based on the 171 respondents, this study discovered that there is a significant difference between the type of residence with the fear of crime $(t(146.34)=-8.79, p<0.05)$, where respondents who lived at individual gated residences (IGR) $(M=5.84, S D=1.23)$ exhibited a higher fear of crime when compared to respondents occupying individual non-gated residences (INR) ( $M=3.85, S D=1.66)$. Among the dimensions of fear of crime $(F O C)$, it discovered that all FOC dimensions, namely, CPR, CS, PE, SE and VIC were higheringated residences. This based on the mean scores registered by these dimensions; $C P R(I G R=3.46$, INR=1.86), CS (IGR=3.06, INR=1.30), PE (IGR=5.81, INR=3.86), SE (IGR=6.01, INR=3.99), and $\mathrm{VIC}(I G R=5.80, I N R=3.77)$, where the values were all relatively higher in individual gated residences (IGR) when compared to individual non-gated residences (INR). These findings are as illustrated in Figure 2.

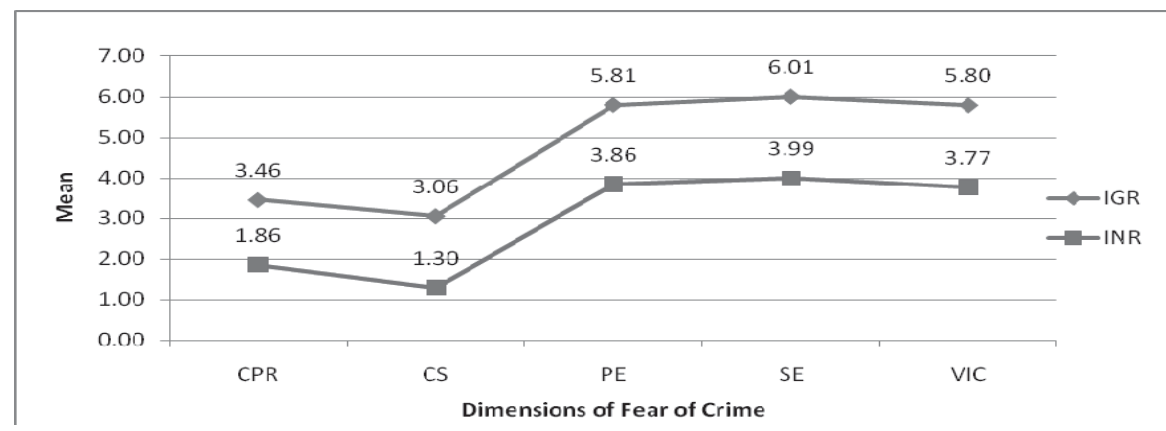

Figure 2: Dimensions of Fear of Crime

Note: IGR=individual gated residences, INR= individual non-gated residences, $C P R=$ crime problem in residential areas, $C S=$ crime-specific, $\mathrm{PE}=$ physical environment,

$\mathrm{SE}=$ social environment, $\mathrm{VIC}=$ indirect victimization

These findings have refutes the statement made by Blakely and Synder (1997) that residents who inhabit gated residential areas have a lower fear of crime when compared to those in residential areas that do not have fencing elements. Nevertheless, this difference in findings believed to be linked with the application of the fencing element in itself. The gated element based on the scope of the study conducted by Blakely and Synder (1997) involved the installation of fencing elements surrounding the housing area which forms the community neighborhood, where the application of the fencing element makes it known as a gated 
community. On the other hand, in this study, the application of the fencing elementonly involves individual residential lots alone, without any fencing element installation along the perimeter of the housing area. Besides this, the findings of this study also believed to be directly linked with the local communities of both residential areas (IGR and INR). This is congruent with the study by McMillan and George (1986), where it found that good community relationships within residential neighborhoods are able to reduce fear of crime and at the same time elevate the sense of safety.

In addition, this study also discovered that gender demography registered a significant difference $(t(79)=5.11, p<0.05)$ in INR, where unmarried respondents $(M=6.54, S D=1.70)$ demonstrated a higher sense of fear when compared to married respondents $(M=3.59$, $S D=1.43$ ). This finding contradicts the statement by Hipp (2010) which contended that married residents have a higher fear of crime as they are more concerned about the safety of their family and children. However, the finding of this study implies that the lifestyle of an unmarried respondent influences the level of fear towards crime. This had previously stated by Tseloni and Zarafonita (2008) where it asserted that the lifestyle of an individual will be able to exacerbate his or her fear of crime. This is due to the fact that these individuals might be prone to be involved in issues that connected to disturbances, which may subsequently lead to criminal acts, such as fighting or brawling (Joseph, 1997).

For the demography concerning duration of stay at the residential area, this study discovered a significant difference in terms of fear of crime in Individual Non-gated Residences (INR) $(F(4,76)=4.30, P<0.05)$, where it found that the older a respondent is the lower the fear of crime reported. This finding is contrary to the study conducted by Austin, Furr and Spine (2002), where they found that as a respondent gets older in terms of age, a higher level offear of crime registered due to factors concerning the reduced ability of the respondent's physical body to ward off harm or enemies. However, this study discovered findings that are converse to this previous study. This believed to have a connection with the respondent's knowledge about the surrounding residential area in the context of crime occurrences. This is as discovered by Hipp (2010), where the duration of an individual's stay in a housing area will influence his or her fear of crime as they become well versed about their residential neighborhood in terms of crime incidences. This finding is as shown in Figure 3.

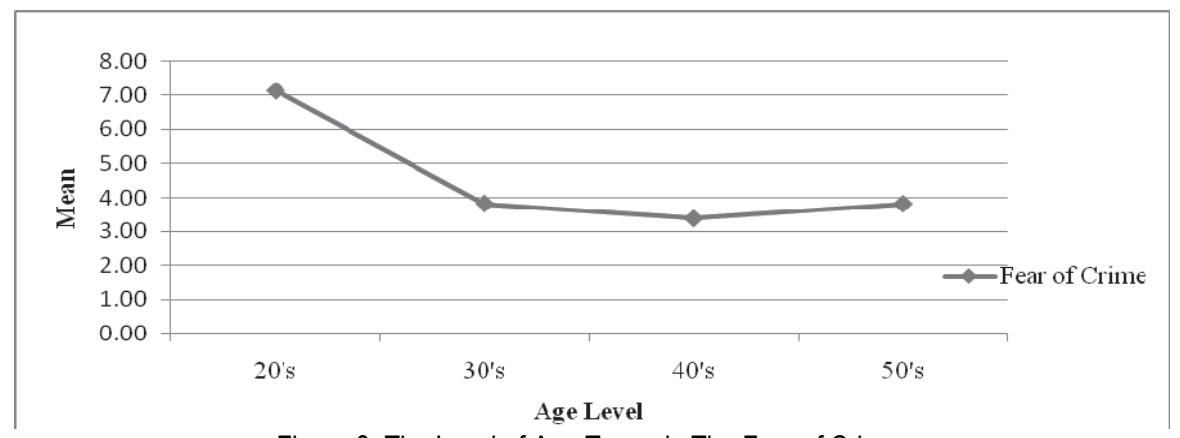

Figure 3: The Level of Age Towards The Fear of Crime 


\subsection{Conclusion}

The main objective of this study was to investigate the fear of crime in individual gated residences (IGR) and individual non-gated residences (INR). The findings of this study prove that within the context of gated and non-gated individual residences, respondents who occupy individual gated residential areas demonstrate a higher fear of crime when compared to their counterparts who live in non-gated residential areas. This situation believed to be linked to factors involving community relations, lifestyle and surrounding environment, which all influence the fear of crime. Therefore, it is pertinent that a more comprehensive and detailed study undertaken in the future regarding community relations and its correlation to fear of crime, in terms of the connection and influence between these two elements in residential neighborhoods, especially within the context of individual gated and non-gated residences.

\section{Acknowledgement}

In realizing this study, the researchers would like to thank the Royal Malaysian Police (PDRM), the Malaysia Crime Prevention Foundation (MCPF), the Kuala Lumpur City Hall (DBKL) as well as the Urban and Rural Planning Department (JPBD) in giving their fullest cooperation and support towards the success of this study. The researchers would also like to acknowledge and thank the UiTM education scholarship administrators for endowing and sponsoring the study programme under the doctoral scheme and the Institute of Postgraduate Studies (IPS) in USM for providing a graduate research grant to assist in the undertaking of this study. A special thanks also accorded to all the respective residents within the study areas for their invaluable cooperation.

\section{References}

Atkinson, Blandy, S., Flint, J., \& Lister, D. (2004). Gated Communities in England. London: Office of The Deputy Prime Minister.

Austin, D. M., Furr, L. A., \& Spine,M. (2002). TheEffects of Neighborhood Conditions on Perception of Safety. Journal of Criminal Justice, 30, 417-427.

Banks, M. (2005). Spaces of (in) Security: Media and Fear of Crime in a Local Context. Crime, Media, Culture, 1(2), 169-187.

Blakely, \& Snyder. (1997). Divided We Fall Gated and Walled Communities in the United States. New York: Princeton Architectural Press.

Bureau of Justice Statistics. (2002). Criminal Victimization in the United States, 2001:ANational Crime Victimization Report. Washington, DC: U.S. Government Printing Office.

Ferraro, K. F., \& LaGrange, R. (1987). The Measurement of Fear of Crime.Sociological Inquiry, 57, 70-101.

Fowler, F. J., Jr., , \& Mangione, T. W. (1986). A Three-Pronged Effort to Reduce Crime and Fear of Crime : 
Md Sakip, S.R., et.al. / Asian Journal of Environment-Behaviour Studies (ajE-Bs), 3(7) Mar / Apr 2018 (p.81-89)

The Hartford Experiment In D.P Rosenbaum (Ed.),Community crime prevention: Does it work? Newbury Park, CA: Sage Publications, 87-108.

Gibson, C. L., Zhao, J., Lovrich, N. P., \& Gaffney, M. J. (2002). Social Integration, Individual Perceptions of Collective Efficacy and Fear of Crime in Three Cities. Justice Quarterly, 19, 537-564.

Hale, C. (1996). Fear of Crime: A Review of The Literature International Review of Victimology, 4, 79-150.

Harang, M. (2003). The Improvement of the Quality of Life in Residential Areas: The Policy Tree.

Hipp, J. R. (2010). "Resident Perceptions of Crime and Disorder: How Much is "Bias", and How Much is Sosial Environment Differences?" American Society of Criminology 48(2): 475-508.

JPBD. (2009). Draf Akhir Laporan Teknikal 'Gated and Guarded Community'. Kuala Lumpur: MN Consult.

Joseph, J. (1997). "Fear of Crime Among Black Elderly." Journal of Black Studies 27(5): 698-717.

McMillan, D. W., \& George, D. M. C. (1986). Sense of Community: A Definition and Theory. Journal of Community Psychology, 14, 6-23.

Minnery, J. R., \& Lim, B. (2005). Measuring Crime Prevention Through Environmental Design. Journal of Architectural and Planinng Research, 22(4), 330-341.

Nasar, \& Fisher, B. (1993). 'Hot Spots' of Fear and Crime: A Multi-Method Investigation. Journal of Environmental Psychology, 13, 187-206.

O'Shea, T. C. (2006). "Physical Deterioration, Disorder, and Crime." Criminal Justice Policy Review 17(2): 173-187.

Pain, R. (2000). Place, Social Relations and The Fear of Crime: A Review.

Progress in Human Geography, 24(3), 365-387.

Putrajaya, P. (2009). Laporan Pemeriksaan; Draf Rancangan Struktur Putrajaya. Putrajaya: Perbadanan Putrajaya.

Reid, S. T. (2000). Crime and Criminology (Ninth ed.). U.S: McGraw-Hill Higher Education.

Renauer, B. C. (2007). Reducing Fear of Crime: Ctizen, Police or Government Responsibility? Journal Police Quarterly, 10(1), 41-62.

Roslan Talib. (2009). Residents Satisfaction SURVEY on the Selected Goverment's Double Storey Terrace Housing Units at Precinct 9, Federal Territory of Putrajaya, Malaysia - Precinct with No-Fence Concept. Paper presented at the Conference Name|. Retrieved Access Date|. from URL|.

Ross, C. E., \& Jang, S. J. (2000). Neighborhood Disorder, Fear, and Mistrust: The Buffering Role of Social Ties with Neighbors. American Journal of Community Psychology, 28(4), 401-420.

Schneider, R. H., \& Kitchen, T. (2007). Crime Prevention and The Built Environment. New York: Routledge, New York.

Setha Low. (2004). Behind the Gates: Life, Security, and the Pursuit of Happiness in Fortress America: Routledge Madison Avenue New York.

Spinks, C. (2001). A New Apartheid? Urban Spatiality, (Fear of) Crime, and Segregation in Cape Town, South Africa. London: Development DESTIN Studies Institute. 
Md Sakip, S.R., et.al. / Asian Journal of Environment-Behaviour Studies (ajE-Bs), 3(7) Mar / Apr 2018 (p.81-89)

Stiles, B. L., Halim, S., \& Kaplan, H. B. (2003). Fear of Crime Among Individuals With Physical Limitations. Journal Criminal Justice Review, 28(2), 232-253.

Supt Goh Boon Keng. (2006). The Economic and Social Costs of Crime. Journal of the Kuala Lumpur Royal Police College, 1-19.

Thuillier, G. (2003). Gated Communities in The Metropolitan Area of Buenos Aires: A Challenge For Town Planning. Paper presented at the Conference Name|. Retrieved Access Date|. from URL|.

Tseloni, A. and C. Zarafonitou (2008). "Fear of Crime and Victimization; A Multivariate Multilevel analysis of Competing Measurements." European Journal of Criminology 5(4): 387-409.

UPE. (2004). Kualiti Hidup Bandar di Malaysia. Kuala Lumpur: Unit Perancang Ekonomi, Jabatan Perdana Menteri.

Welsh, B. C., \& Hoshi, A. (2002). Communities and Crime Prevention. In Evidence-Based Crime Prevention. New York: Routledge. 